\title{
Reflexión sobre la exhortación apostólica Evangelii Gaudium*
}

\author{
Felipe Augusto Martínez Mora**
}

Recibido: 31 de octubre de 2017 • Aprobado: 27 de noviembre de 2017

\section{Resumen}

La propuesta del papa Francisco para la renovación de la Iglesia es la misión. Tomamos como punto de partida la invitación del papa Francisco a salir al encuentro con el otro para proponer la reflexión sobre la incidencia que tiene en él la cuestión teológica. Es necesario, urgente, que la misión modifique la acción pastoral y el lenguaje teológico, ya que el decir y el hacer están estrechamente unidos. Dios, Jesucristo, el hombre, la cultura y las consecuencias éticas de la transformación misionera son los temas que se pretenden abordar en este artículo. El papa Francisco afirma que la misión es transformadora y que hay que dejar todo de manera distinta a como estaba, la teología tiene que dejarse interpelar por la praxis de la evangelización y a su vez la evangelización tiene que alimentarse de la teología que manifiesta la grandeza de Dios y el hombre.

Palabras clave: Francisco, evangelización, alegría, conversión, Iglesia.

* Este artículo es el resultado de la investigación del autor. DOI: http://dx.doi.org/ 10.15332/s2011-9771.2017.0002.07

** Licenciado en Filosofía de la Fundación Universitaria San Alfonso. Diplomado en música pastoral en la Corporación Universitaria Minuto de Dios y Teólogo de la Universidad Santo Tomás. Correo electrónico: felipemartinez0577@gmail.com 


\title{
Reflection on the apostolic exhortation Evangelii Gaudium
}

\begin{abstract}
The proposal of Pope Francis for the renewal of the Church is the mission. We take as our starting point the invitation of Pope Francis to go out to meet the other to propose a reflection on the impact that the theological question has on him. It is necessary, urgent, that the mission modifies the pastoral action and the theological language, since saying and doing are closely related. God, Jesus Christ, the man, the culture and the ethical consequences of missionary transformation are the topics that are to be addressed in this article. Pope Francis affirms that the mission is transformative and that everything must be left differently than it was, theology has to allow itself to be questioned by the praxis of evangelization and in turn evangelization must feed on the theology that expresses the greatness of God and man.
\end{abstract}

Keywords: Francis, evangelization, joy, conversion, Church.

\section{Reflexão sobre a exortação apostólica Evangelii Gaudium}

\section{Resumo}

A proposta do papa Francisco para a renovação da Igreja é a missão. Tomamos como ponto de partida o convite do papa Francisco para sair ao encontro com o outro para propor a reflexão sobre a incidência que tem nele a questão teológica. É necessário, urgente, que a missão modifique a ação pastoral e a linguagem teológica, dado que o dizer e o fazer estão estreitamente unidos. Deus, Jesus Cristo, o homem, a cultura e as consequências éticas da transformação missioneira são os temas que se pretende abordar neste artigo. O papa Francisco afirma que a missão é transformadora e que se deve deixar tudo de maneira distinta a como estava, a teologia tem que se deixar interpelar pela práxis da evangelização e a sua vez a evangelização tem que se alimentar da teologia que manifesta a grandeza de Deus e o do homem.

Palavras-chave: Francisco, evangelização, alegria, conversão, Igreja. 


\section{Introducción}

La Iglesia ha escuchado el llamado a la misión desde los inicios del cristianismo. Cuando en el siglo II se vivió la persecución que impedía la acción misionera y su trabajo evangelizador se veía reducido y opacado notoriamente, más tarde la sociedad ofreció el espacio para abrir las puertas a la misión (Lafont, 1994). Justamente, los estudios históricos nos permiten reconocer claramente que es la misión donde la Iglesia halla identidad y donde se viabiliza grandemente y que uno de sus pilares más importantes, que responde a la universalidad a la que está llamada, se encuentra en la misión. En el momento en que la Iglesia apacigua este impulso deja de irradiar el rostro glorioso y misericordioso de Cristo, reflejando el rostro de una Iglesia donde sobresale el egoísmo humano.

Efectivamente el Concilio Vaticano II, convocado por Juan XXIII (1962-1965) ${ }^{1}$ ha sido esperanza para la humanidad y ha renovado la conciencia y la importancia de la misión. Este tema lo encontramos en documentos concretos tal como Ad Gentes y es además tema transversal que se funde en el misterio y sacramentalidad de la Iglesia. Es la Lumen Gentium y Gaudium et spes, que nos muestra un concepto novedoso de misión, en el que se exhorta a la Iglesia a ir al encuentro de las comunidades e iniciar un proceso de evangelización de las culturas.

Ciertamente, fue Juan Pablo II quien acogió este gran reto en su encíclica Redemptoris Missio (1990), dando nuevas pautas para afrontar la difícil situación. Ahora se trata no solo de la misión ad gentes sino de una re-evangelización o una nueva evangelización, esta categoría la empleó Juan Pablo II en Santo Domingo en el año 1984, ya que es una urgencia responder al llamado y a la actividad misionera para los tiempos modernos.

La encíclica insiste en los desafíos que debe enfrentar la Iglesia, específicamente en lo referente a la evangelización de aquellos grupos que no han recibido la fe cristiana y de aquellas personas que, aún recibiéndola, deben ir al encuentro del Reino de Dios; realidad que se debe enfrentar con una misión ad intra. Ya que han sido variadas las dificultades internas y externas, que han llevado a la crisis eclesial en la modernidad, es preciso que el impulso misionero se renueve y que este momento sea fortalecido dando el primer paso al encuentro con el otro.

1 El Concilio Ecuménico de la Iglesia Católica (encuentro de todos los obispos), fue convocado por el papa Juan XXIII en 1962 y clausurado por el papa Pablo VI en 1965. 
Con el papa Francisco ${ }^{2}$ la misión vuelve a ser el centro en el panorama de la Iglesia. A pesar de ello encontramos en la actualidad una diferencia: esta vez se relaciona a la transformación de la Iglesia. Significa la senda de conversión que la Iglesia debe recorrer. Dicho de otra manera, no se trata solamente de llevar el Evangelio a quienes no lo conocen o poco saben de él, es la ocasión urgente de hacer una renovación y transformación en la Iglesia. Como expresa Francisco:

Sueño con una opción misionera capaz de transformarlo todo, para que las costumbres, los estilos, los horarios, el lenguaje y toda estructura eclesial se convierta en un cauce adecuado para la evangelización del mundo actual más que para su autopreservación (2013a, EG 27).

Estamos ante un llamado al que deberíamos agregarnos si tenemos una vocación particular o si nos queda tiempo para dedicarle. El papa Francisco anhela que la misión sea algo más, un proyecto de vida, una columna de la Iglesia. Para Francisco, "la salida misionera es el paradigma de toda obra de la Iglesia" (EG 15) ${ }^{3}$ que todo cristiano debe "asumir en cualquier actividad que se realice" (EG 18) ya que la intención es que la Iglesia se constituya "en todas las regiones de la tierra en un estado permanente de misión" (EG 25). Es en la misión donde podemos encontrar la renovación de toda la Iglesia, desde la parroquia, la diócesis y su institución eclesial, llegando hasta al mismo obispo de Roma (cf. EG 28-33).

El presente artículo pretende reconocer las apuestas teológico-praxeológicas que el papa plantea para que la Iglesia se renueve por medio de la misión. Con este intuito, en un primer momento, nos aproximamos a la figura del primer papa latinoamericano, con la finalidad de ir descubriendo sus apuestas teológico-praxeológicas para una renovación eclesial. En seguida, tomamos como punto de referencia la encíclica Evangelii Gaudium (EG), por considerar que en ella se encuentran las claves para la práxis misionera de la Iglesia. Las dimensiones éticas de la acción misionera serán abordadas en un tercer punto para finalmente presentar algunas consideraciones conclusivas. En todo este trayecto tomaremos como eje transversal, el tema de la alegría en el encuentro con Jesús y con el otro, imperativo ético para una verdadera renovación eclesial.

2 Cardenal argentino Jorge Mario Bergoglio, elegido como el sumo pontífice número 266 de la Iglesia católica, el 13 de marzo del 2013.

3 Evangelii Gaudium (EG). 
Claro está, que no se agotará el tema en este escrito. Es solo una pequeña muestra a la que todo cristiano está invitado a seguir profundizando. Ya que este llamado es para todos sin exclusión:

Cada cristiano y cada comunidad discernirá cuál es el camino que el Señor le pide, pero todos somos invitados a aceptar este llamado: salir de la propia comunidad y atreverse a llegar a todas las periferias que necesitan la luz del Evangelio (EG 20).

\section{El cónclave dio un obispo a Roma, lo buscaron "en el fin del mundo"}

Con estas palabras el nuevo obispo de Roma dio inicio a su mandato (Bergoglio, 2013). El primer papa latinoamericano, fue elegido el 13 de marzo de 2013, el Espíritu Santo sopló hacia el sur, hacia Argentina. Cada palabra que ha pronunciado desde su ministerio petrino ha sido novedosa y ha llegado al corazón de la gran mayoría de los cristianos. Acontecimientos como la Jornada Mundial de la Juventud en el 2013 y el auténtico Viaje a Tierra Santa en el 2014; son una ventana que ha mostrado lo que desde entonces ha sido su ministerio pastoral que se resume en la exhortación EG.

Las raíces del pontificado de Francisco están en la figura del jesuita Jorge Mario Bergoglio y su acción misionera y pastoral como sacerdote y como obispo. Su huella está impresa en el proyecto misionero de la V Conferencia General del Episcopado de América Latina y el Caribe que se celebró en el año 2007 en Aparecida, Brasil. Al conocer a la Iglesia latinoamericana enunciada en Aparecida, se puede llegar a entender de mejor manera el pensamiento de Francisco y la teología de la Argentina moderna.

Cuando Francisco salió al balcón se le notó nervioso y emocionado, su saludo a los peregrinos fue como si saludara a un hermano de camino. Pidió la bendición al pueblo reunido en la plaza de San Pedro y se inclinó para recibirla. Su sermón rompió el protocolo. Expresó estas palabras a todos sus oyentes: “¡Cómo me gustaría una Iglesia pobre, para los pobres!". Ello recuerda una verdad tan simple como olvidada: "Un poco de misericordia hace al mundo menos frío y más justo". Esos minutos de Francisco en el balcón describen el modo en que deseaba la renovación de la Iglesia, y la manera en que quería comunicar el mensaje de la salvación de una manera diferente. "Los enormes y veloces cambios 
culturales requieren que prestemos una constante atención para intentar expresar las verdades de siempre en un lenguaje que permita advertir su permanente novedad" (Francisco, 2013a, EG 41).

Francisco no pretende adaptar un lenguaje para que todos entiendan la exigencia del mensaje, ni maquillarlo maquillarlo para que sea más agradable a los oídos de los cristianos. Su propuesta va más allá, exige coherencia de vida entre hechos y palabras avalada por la simplicidad de Evangelio. Además, tiene trascendencia ética y moral. La misión es el instrumento del que fluirá el anuncio de Jesucristo, Hijo de Dios vivo. "Si pretendemos poner todo en clave misionera, esto también vale para el modo de comunicar el Evangelio" (EG 34). Es necesario apropiarse del mensaje del amor que brota de la misma fe.

La aceptación del primer anuncio, que invita a dejarse amar por Dios y a amarlo con el amor que Él mismo nos comunica, provoca en la vida de la persona y en sus acciones una primera y fundamental reacción: desear, buscar y cuidar el bien de los demás (EG 178).

No serán las palabras o las buenas intenciones las que le den una transformación a la Iglesia. Tenemos el conocimiento y la experiencia, sabemos lo que esto significa. La importancia de las palabras y los hechos deben ser coherentes, esta coherencia es muy importante a la hora de evangelizar ya que la palabra adquiere una dimensión ética y solo así logra brotar el compromiso con el Evangelio. Francisco advierte que olvidar esto hace difícil dar testimonio y no permite una transformación desde lo más profundo del corazón de la Iglesia. El siguiente párrafo indica el vínculo que existe entre comunidades eclesiales pobres y lo que piensa Francisco.

Cualquier comunidad de la Iglesia, en la medida en la que pretenda subsistir tranquila sin ocuparse creativamente y cooperar con eficiencia para que los pobres vivan con dignidad y para incluir a todos, también correrá el riesgo de la disolución, aunque hable de temas sociales o critique a los gobiernos. Fácilmente terminará sumida en la mundanidad espiritual, disimulada con prácticas religiosas, con reuniones infecundas o con discursos vacíos (EG 207).

Precisamente la relación que hay entre palabras y hechos conduce a considerar que uno de los aspectos en donde se dará la transformación misionera de la 
Iglesia está en la unión que hay entre teología y pastoral. Estas son dos realidades que no podemos separar. La pastoral no puede ocultarse en un hacer que la haga intocable ante el pensar teológico. Sin embargo, la teología no puede mostrar sus tratados de manera exclusiva, de manera que la verdad proclamada fuese únicamente suya, ya que ella tiene igualmente un compromiso ético. Es verdad que se han dado pasos que nos ayudan a unir estos dos puntos de vista. No obstante, Francisco en la EG nos hace la invitación para que profundicemos esas dos alternativas y aquí está el núcleo fundamental para la renovación misionera dentro de la Iglesia.

\section{La exhortación Evangelii Gaudium}

Precisamente la alegría del Evangelio es un documento de teología pastoral o teología práctica. La teología pastoral es una rama de la teología práctica; primordialmente es una ciencia o disciplina teológica que comprende la acción pastoral y evangelizadora de la Iglesia desde la fe. Esta acción pastoral actualiza la praxis de Jesús y tiene como horizonte el Reino de Dios. El Reino es un don del cual Dios es quien ha tomado la iniciativa para llamar a la conversión. Quien acoge el Reino está acogiendo al mismo Cristo y por consiguiente tiene sus mismos sentimientos, actitudes y comportamientos (cf. Fil 2,5). La acción pastoral es animada por el Espíritu Santo a proclamar la Resurrección de Cristo y a anunciar la Buena Nueva a los pobres, renovándose a sí misma desde la íntima unión con la Santísima Trinidad y con los hermanos, con la tarea de construir el Reino de Dios en sus vidas.

La EG es un texto con gran particularidad en su estilo y contenido. Contiene introducción seguida de cinco capítulos organizados en 288 numerales, enriquecida con 227 citas textuales de la Biblia y 217 notas de pie de página con información adicional que orientan su lectura.

Con el texto, Francisco responde al encargo de realizar el documento con los aportes en el Sínodo de Obispos del año 2012 sobre la nueva evangelización para la transmisión de la fe cristiana (EG 16). Contiene las contribuciones de la reflexión hecha con un programa que promueve la "nueva salida misionera" (EG 20). Aunque su temática es limitada (EG 17), las amplía y profundiza porque anhela "perfilar un determinado estilo evangelizador que invito a asumir en cualquier actividad que se realice" (EG 18).

El sentido programático de su exhortación es claro: 
No obstante, destaco que lo que trataré de expresar aquí tiene un sentido programático y consecuencias importantes. Espero que todas las comunidades procuren poner los medios necesarios para avanzar en el camino de la conversión pastoral y misionera, que no puede dejar las cosas como están (EG 25).

La conversión pastoral y misionera mueve a discernir las muchas cosas que no pueden seguir como están y orientar su transformación.

Si se pudiera resumir en dos frases el proyecto misionero de Francisco, serían las siguientes: "Sueño con una opción misionera capaz de transformarlo todo" (EG 27) y, "la actividad misionera representa aún hoy día el mayor desafío para la Iglesia" (EG 15). Se percibe la gran contribución que ofrece a la trasformación misionera de toda la Iglesia el impulso de la conversión orientada a la misión continental en las periferias de toda Latinoamérica.

Se encuentran en la estructura del texto, que el sumo pontífice eligió, siete grandes temas ${ }^{4}$ distribuidos en cinco capítulos. En el primer capítulo encontramos "la transformación misionera de la Iglesia" (EG 19-49), aquí se desarrolla una eclesiología y su núcleo es la conversión misionera para anunciar "la frescura original del Evangelio" (EG 19), su "núcleo central" (EG 34).

El segundo capítulo, "en la crisis del compromiso comunitario", Francisco hace una lectura profética de los signos de los tiempos y todo aquello que genera exclusión social y desigualdad; también, Francisco hace un discernimiento sobre las tentaciones que interrumpen el entusiasmo en el apostolado de la Iglesia (EG 50-109).

En el tercer capítulo, "el anuncio del Evangelio", el gran protagonista y sujeto histórico de la evangelización y de la proclamación del Kerigma es el Pueblo de Dios: la fuerza evangelizadora de la piedad popular, la predicación dentro de la homilía, la conversión personal, la catequesis kerygmática y mistagógica, el acompañamiento personal de los procesos de crecimiento, en torno a la Palabra de Dios (EG 110-175).

4 "Aquí he optado por proponer algunas líneas que puedan alentar y orientar en toda la Iglesia una nueva etapa evangelizadora, llena de fervor y dinamismo. Dentro de ese marco, y en base a la doctrina de la Constitución dogmática Lumen gentium decidí, entre otros temas, detenerme largamente en las siguientes cuestiones: a) La reforma de la Iglesia en salida misionera; b) Las tentaciones de los agentes pastorales; c) La Iglesia entendida como la totalidad del Pueblo de Dios que evangeliza; d) La homilía y su preparación; e) La inclusión social de los pobres; f) La paz y el diálogo social; g) Las motivaciones espirituales para la tarea misionera" (EG 17). 
En el cuarto capítulo, "la dimensión social de la evangelización", hace una reflexión entre la unión que existe entre el Kerigma y el compromiso social que debe buscar la dignidad humana, e impulsar el bien común, poniendo atención especial en la inclusión social y los diálogos para contribuir a encontrar la paz (EG 176-258). El quinto y último capítulo "evangelizadores con espíritu", plantea los fundamentos de la evangelización como animadora de la misión de los bautizados (EG 259-288). La fuerza de la exhortación en este capítulo despliega la mutua relación entre teología, pastoral y espiritualidad.

Existe conexión entre diferentes capítulos. La primera parte del capítulo II, que trata sobre la realidad social, tiene correspondencia con la dimensión social del Evangelio en el capítulo IV con mayor extensión; en la segunda parte del capítulo II se da un vistazo a la realidad eclesial, que tiene relación con el capítulo V. Y el capítulo III considerado como la parte central del tema expuesto brevemente en el capítulo I y por esto lleva el título de la exhortación: el anuncio del Evangelio (Fernández y Rodari, 2014, p. 31).

En la exhortación apostólica (EG) el papa Francisco nos hace una invitación a todos los cristianos, a comprometernos y a que participemos en la evangelización como tarea fundamental de todo bautizado. Es por este motivo que intentaré dar respuesta a interrogantes que surgen desde la misma exhortación: ¿Qué implicaciones tiene esta exhortación apostólica en el discurso sobre Dios? ¿Cuáles son los efectos antropológicos? ¿Cuáles son las dimensiones éticas en la renovación misionera?

\subsection{Jesucristo nos revela a Dios Padre}

Francisco en su discurso nos quiere mostrar al Dios de Jesucristo. Aunque el texto no profundiza exactamente en este tema, podemos descubrirlo en la base de cada palabra de la propuesta misionera que nos hace el sumo pontífice. Ante todo, Francisco señala que esta es una nueva etapa para evangelizar y que su sello debe ser la alegría (cf. EG 1). Además, es una alegría cargada del amor, de la misericordia de Dios. "Dios no se cansa nunca de perdonar, somos nosotros los que nos cansamos de acudir a su misericordia" (EG 3).

Quien ha tenido un encuentro personal con Dios experimenta un cambio transformador por medio de la misericordia divina. Y la forma en que se puede extender esta experiencia es dándola a conocer, anunciando el mensaje de salvación de Jesucristo. Con seguridad podemos afirmar que la misión no puede llegar a ser nunca un proselitismo partidario, esta debe ser un llamado al encuentro personal con el Dios de la vida: 
Los cristianos tienen el deber de anunciar [a Dios] sin excluir a nadie, no como quien impone una nueva obligación, sino como quien comparte una alegría, señala un horizonte bello, ofrece un banquete deseable. La Iglesia no crece por proselitismo sino por atracción" (EG 14).

La razón de la misericordia halla su origen en el misterio de la Encarnación del Hijo de Dios, es el misterio de Dios que asumió la condición humana para hacerse hombre y salvar a toda la humanidad. La exhortación recupera la novedad de la propuesta por los evangelios en este sentido. La EG describe al Jesús que vivió con la gente, que caminó con su pueblo haciendo milagros, al que sanó a los enfermos y liberó a los poseídos, al que enseñó y predicó el Reino de Dios con autoridad, ese Jesús que atraía las miradas de muchos y que despertaba la esperanza de su pueblo, ese Jesús que tuvo misericordia con la multitud que andaba como ovejas sin pastor, al que perdonó sin juzgar y que anunció la Buena Nueva invitando a la conversión.

Para la multitud, poder llamar a Dios Abbá, es decir, Padre, padre mío, papaíto, papá, fue una de las grandes novedades que trajo Jesucristo y que contenían un gran poderío. Es por eso que Francisco sostiene que "el Hijo de Dios, en su encarnación, nos invitó a la revolución de la ternura" (EG 88). Cuando se identifica la misericordia con el relativismo moral o el teológico significa no comprender que esta acompaña los procesos de la humanidad.

Por lo tanto, sin disminuir el valor del ideal evangélico, hay que acompañar con misericordia y paciencia las etapas posibles de crecimiento de las personas que se van construyendo día a día... Un pequeño paso, en medio de grandes límites humanos, puede ser más agradable a Dios que la vida exteriormente correcta de quien transcurre sus días sin enfrentar importantes dificultades (EG 44).

Antes bien, Francisco señala el grave peligro de caer en el relativismo porque genera ausencia de misericordia y la persona que cae en este se hace dura de corazón. "Este relativismo práctico es actuar como si Dios no existiera, decidir como si los pobres no existieran, soñar como si los demás no existieran, trabajar como si quienes no recibieron el anuncio no existieran" (EG 80). Quien obra, toma decisiones e imagina su vida basado en el egoísmo y en el individualismo, pensando en adquirir poder, seguridad económica y un estatus dentro de la sociedad y el mundo. No le preocupa alcanzar el Reino de Dios y está vacío. Las consecuencias teológicas del enfrentamiento de este doble relativismo es que en la práctica se plantea la división entre el decir y el hacer. 
Esta es la misión con el sello de la alegría misericordiosa, es una llamada a reflexionar continuamente la forma en que se enseñan los tratados de Dios y la cristología. Como lo dice W. Kasper (2012) cuando indica que la falta de este tema en los escritos sobre Dios es inconveniente. Realiza un acto de contrición enfatizando la

Alarmante constatación de que este tema -fundamental para la Biblia y de actualidad para la experiencia contemporánea de la realidad-solo ocupa, en el mejor de los casos, un lugar marginal en los diccionarios enciclopédicos y manuales de teología dogmática (p. 19).

No se puede observar únicamente como uno de los atributos que proceden de la esencia metafísica de Dios salvo que tenemos la responsabilidad de concederle prioridad en la historia de la salvación. Sin embargo, no es un tema secundario en el momento que contemplamos a Jesucristo. No es posible introducirnos en el fondo transformador de la misericordia si no recobramos el misterio de la Encarnación y su obrar en la historia de la humanidad.

\subsection{Consecuencias antropológicas en la cultura}

Dios ofrece la salvación al hombre de una manera particular. Francisco menciona que la acción de Dios es recibida por el hombre en una determinada cultura. "La gracia supone la cultura, y el don de Dios se encarna en la cultura de quien lo recibe" (EG 115).

A lo mejor pueda parecer extraño para algunos la modificación del término clásico y que haya sido reemplazada la palabra naturaleza por cultura. Esta afirmación está fundamentada en la GS 53. También es posible reconocerla en textos de Pablo VI como la encíclica Evangelii Nuntiandi (1975, EN 20) y textos de Juan Pablo II como la encíclica Evangelium Vitae (1995, EV 78), entre otros. Aunque no siempre ha sido tenida en cuenta en la reflexión teológica y en la práctica pastoral, son varias las consecuencias que resultan. Antes que nada, se descubre en estos párrafos una exaltación a las diferentes formas de vida que el ser humano ha generado a lo largo de la historia.

Exaltación que se transforma en un clamor al entender la cultura como una manera de vivir el cristianismo, ya que este "no tiene un único modo cultural, sino que (...) llevará consigo también el rostro de tantas culturas y de tantos pueblos en que ha sido acogido y arraigado" (Francisco, 2013a, EG 116). Tenemos que reconocer que la diversidad transforma el quehacer de la Iglesia y que, a la 
vez, implica comprometerse en predicar a Jesús teniendo en cuenta el contexto de cada cultura y su pluralidad. "Lo que debe procurarse, en definitiva, es que la predicación del Evangelio, expresada con categorías propias de la cultura donde es anunciado, provoque una nueva síntesis con esa cultura" (EG 129).

De esta manera se fractura, se rompe la argumentación, que encasilla al cristianismo en una cultura establecida. No obstante, de ninguna manera se debe entender esto como una agresión o un intento de fomentar la división de la Iglesia. Tampoco se trata de relacionarlo como un sentir antirromano. Francisco sugiere la diversidad en clave teológica de esta manera:

No haría justicia a la lógica de la encarnación pensar un cristianismo monocultural y monocorde. Si bien es verdad que algunas culturas han estado estrechamente ligadas a la predicación del Evangelio y al desarrollo de un pensamiento cristiano, el mensaje revelado no se identifica con ninguna de ellas y tiene un contenido transcultural (EG 117).

Para dar valor a los anhelos más hondos del corazón del ser humano la norma que asumimos es el misterio de Dios, que se hizo hombre en Jesucristo y no una forma cultural por más desarrollada o perfecta que aparente ser. Esto significa tener un corazón abierto para que Dios obre y no se interrumpa su acción por esos esquemas mentales que solemos llevar consigo algunos cristianos. "A veces en la Iglesia caemos en la vanidosa sacralización de la propia cultura, con lo cual podemos mostrar más fanatismo que auténtico fervor evangelizador" (EG 117).

Afirmar esto en cualquiera de los países de América Latina, conlleva consecuencias particulares. Al haber nacido en una región que se representa como un pueblo dentro de muchos pueblos. A partir de la primera predicación del Evangelio se presenta este gran reto para la Iglesia: apreciar independencia cultural del pueblo recién nacido que a su vez transmite con veracidad el mensaje de salvación.

Hoy, el desafío continúa siendo actual. El pueblo enorme que es nuestro continente, es valioso en manifestaciones que se sostienen y amparan en la fe del Dios Uno y Trino, en el Dios de Jesucristo, y en la Virgen María, nuestra Madre.

\section{Dimensiones éticas en la renovación misionera}

La misión desde sus inicios ha implicado gran contenido teológico e indiscutiblemente responsabilidad social, con resultados éticos que saltan a la vista. No cabe 
duda, como lo hemos venido indicando, la fuente de donde fluye este compromiso es el mismo Dios Uno y Trino que se abajó en Jesucristo para hacerse cercano a los hombres y a las grandes incógnitas de la vida. Resulta paradójica esta condición del ser de Dios en su comunicación con el ser humano, convencimiento de fe que siempre tuvo el pueblo de Israel y que llegó a su culmen extraordinariamente en la Encarnación del Hijo de Dios, Jesús de Nazaret.

Anteriormente hemos mencionado algo sobre esta relación. En el capítulo IV de la EG encontramos que se amplía el asunto de la dimensión social de la evangelización. La proclamación del Reino de Dios y amar a Dios y al prójimo, se hacen una realidad tangible que tiene sus consecuencias en este mundo: “En la medida en que Él logre reinar entre nosotros, la vida social será ámbito de fraternidad, de justicia, de paz, de dignidad para todos. Entonces, tanto el anuncio como la experiencia cristiana tienden a provocar consecuencias sociales" (EG 180).

La exhortación a la misericordia mencionada en los Evangelios de Mt 25,40 7,2 y Lc 6,36 que hace referencia a que en la vida del hombre se descubre la posibilidad de que la Encarnación se prolongue, y Francisco explica:

Lo que expresan estos textos es la absoluta prioridad de la 'salida de sí hacia el hermano' como uno de los dos mandamientos principales que fundan toda normal moral y como el signo más claro para discernir acerca del camino de crecimiento espiritual en respuesta a la donación absolutamente gratuita de Dios (EG 179).

En la dimensión ética de la misión encontramos un tema delicado, lo hallamos en el reproche que se hace acerca del uso del dinero. $Y$ esto no es un reproche a circunstancias coyunturales, ni mucho menos se trata de una corrección a las estrategias económicas de la actualidad. Es más bien crítica que conlleva a una consecuencia social. "En definitiva, la ética lleva a un Dios que espera una respuesta comprometida que está fuera de las categorías de mercado" (EG 57). El texto hace la invitación a romper con la lógica del dinero como meta hermenéutica de la antropología y presenta la propuesta de situar al hombre en el centro de estas inquietudes. Ya que el mayor problema aquí estuvo en que se condicionó la verdad y la felicidad del hombre poniendo al dinero en un lugar que nunca le corresponderá. Por ello el lamento determinante: “¡El dinero debe servir y no gobernar!" (EG 58).

Por esto Francisco advierte que esta idolatría hacia el dinero es generadora de escepticismo, desequilibrio y también globalización, además, el papa acusa a quienes oprimen y utilizan al pueblo por medio del dinero. $\mathrm{Y}$ recuerda que, 
aunque se ha dicho que el libre mercado genera equidad y ayuda a la inclusión social, no se ve esto en la realidad: "esta opinión, que jamás ha sido confirmada por los hechos, expresa una confianza burda e ingenua en la bondad de quienes detentan el poder económico y en los mecanismos sacralizados del sistema económico imperante" (EG 54).

La crítica es teológica y conduce a una importante innovación: no debate con el antropocentrismo desde la argumentación teórica, sino con aquel que está constituido por el símbolo del dinero, entendido como organizador de la existencia humana. La propuesta envuelve un cambio de actitud, comprensión por aquellos que padecen hambre, que están marginados de la sociedad y viven la pobreza y muchas veces en miseria. Esto implica cambiar el eje en el que rota el concepto antropológico. Mientras haya niños, hombres y mujeres, dejados de lado en el olvido, tratados inhumanamente, no habrá ningún plan político ni económico que nos conceda, a los "cristianos" vivir tranquilos.

Pero la violencia en la que se hunde el mundo no siempre es la misma, "no sucede solamente porque la inequidad provoca la reacción violenta de los excluidos del sistema, sino porque el sistema social y económico es injusto en su raíz" (EG 59). Aquí se hace un reclamo a que el dinero no sea la columna vertebral del orden social, que subordine a su antojo las relaciones humanas en sus diferentes categorías. Francisco cree que, debido a esto, la crisis financiera ha generado y genera tanta angustia a muchas personas y que su principio no proviene de un mal plan económico sino de una antropología desdibujada por la avaricia de amontonar bienes y riquezas.

Una de las causas de esta situación se encuentra en la relación que hemos establecido con el dinero, ya que aceptamos pacíficamente su predominio sobre nosotros y nuestras sociedades. La crisis financiera que atravesamos nos hace olvidar que en su origen hay una profunda crisis antropológica: ¡la negación de la primacía del ser humano!... La crisis mundial, que afecta a las finanzas y a la economía, pone de manifiesto sus desequilibrios y, sobre todo, la grave carencia de su orientación antropológica que reduce al ser humano a una sola de sus necesidades: el consumo (EG 55).

Ver la manera, la forma en que viven los pobres, nos debe llevar a apelar y analizar la lógica del dinero que simplemente hace al ser humano a un lado, olvidándose que tiene dignidad de persona y es hijo de Dios. Él nos eligió y nos llama a que lo elijamos también. Indudablemente para Francisco la opción por los pobres es teológica antes que cultural, filosófica, política o sociológica. 
Hace la invitación a que aprendamos de su estilo de vida lleno de símbolos que manifiestan el misterio de la vida, y que a pesar de sus sufrimientos, dificultades, limitaciones y necesidades, se deja ver el rostro de la solidaridad, el perdón y el amor. Ya que:

La nueva evangelización es una invitación a reconocer la fuerza salvífica de sus vidas y a ponerlos en el centro del camino de la Iglesia. Estamos llamados a descubrir a Cristo en ellos, a prestarles nuestra voz en sus causas, pero también a ser sus amigos, a escucharlos, a interpretarlos y a recoger la misteriosa sabiduría que Dios quiere comunicarnos a través de ellos (EG 198).

La misión nos llama a cuestionar de manera pacífica las estructuras constituidas a partir de la lógica del Evangelio. Jesucristo nos dio testimonio con sus relaciones durante su vida en la tierra proponiendo un estilo de vida en donde el hombre es el centro y a su vez completamente libre de cualquier esclavitud. Sin embargo, esto implica que asumamos la lógica de la misericordia y del amor, dejándonos convertir, transformar y completar. Aquí lo más importante es que el hombre esté sano y libre como lo describen muchas veces los Evangelios y no que esté atado al cumplimiento estricto de la ley. La misericordia está por encima de cualquier ley. Esto evidencia la construcción de una antropología diferente que parta del fundamento evangélico, y que así mismo se aprovechen las instituciones y adelantos que nos brinda la tradición.

Acontece entonces una consecuencia ética que nos invita a salir de la indiferencia. No estamos solo llamados a modificar una circunstancia que no es normal, sino a contribuir en la construcción de nuevos cimientos, a cooperar poniendo todo de nuestra parte para que la humanidad siga su crecimiento desde la comunión amorosa y misericordiosa que se nos da a los hermanos e hijos de Dios.

\subsection{La alegría de evangelizar como manifestación mística}

Existe una mística que es el corazón palpitante y vivo de la nueva etapa pastoral que se centra en la alegría de evangelizar. “En esta exhortación quiero dirigirme a los fieles cristianos para invitarlos a una nueva etapa evangelizadora marcada por esa alegría e indicar caminos para la marcha de la Iglesia en los próximos años" (EG 1). 
Este título indica la alegría que produce evangelizar, la alegría que mueve a quien lleva el mensaje de Jesús y quien lo recibe con su corazón abierto y receptivo. En la Evangelii Gaudium ${ }^{5}$ la palabra alegría aparece 59 veces, mostrando a su vez la alegría que produce el encuentro personal con el Señor, origen de la misión.

El papa Francisco en su primera encíclica, Lumen Fidei (LF), nos muestra "la alegría de la fe" (LF 47). Esa luz de la fe que alumbra la senda de vida, aún en medio de la noche más oscura, ilumina nuestros pasos (LF 57). Francisco es el mensajero de la alegría. Es la sonrisa de Dios. Es el embajador del amor, del Evangelio.

Él admira profundamente a Pablo VI y aprecia sus dos exhortaciones publicadas en 1975, Gaudete in Domino (GD) y Evangelii Nuntiandi (EN), en las cuales se encuentran coincidencias entre las palabras de esos documentos con las de la su primera exhortación. En la segunda (EN), Pablo VI reflexiona sobre el gozo y el fervor que se da en el apóstol.

Conservemos la dulce y confortadora alegría de evangelizar, incluso cuando hay que sembrar entre lágrimas. Sea esta la mayor alegría de nuestras vidas entregadas... (Que el mundo actual) pueda así recibir la Buena Nueva no a través de evangelizadores tristes y desalentados, impacientes o ansiosos, sino a través de ministros del Evangelio, cuya vida irradia el fervor de quienes han recibido en sí mismos, la alegría de Cristo y aceptan consagrar su vida a la tarea de anunciar el Reino de Dios e implantar la Iglesia en el mundo (EN 80).

En el Documento de Aparecida aparecen las palabras alegría y gozo 90 veces (Süess, 2010, p. 10) y se insiste en la alegría que reflejan los discípulos misioneros de Jesús al comunicar la Buena Nueva. El cardenal Bergoglio como buen jesuita tomó la decisión de citar en la conclusión del documento (A 552) la frase de Pablo VI: la dulce y confortadora alegría de evangelizar (EN 80). Porque en ella se representan las dulces consolaciones que solo vienen del Señor.

En el primer capítulo de la Evangelii Gaudium; “La alegría que se renueva y se comunica" (EG 2-8), pretende salirle al paso a la tristeza individualista y la primera cita mencionada procede de la exhortación de Pablo VI (GD 22 en EG 3). Esto muestra la gran admiración de Francisco por Montini.

5 El nombre completo del documento es: Exhortación apostólica Evangelii Gaudium del santo padre Francisco a los obispos, a los presbíteros y diáconos, a las personas consagradas, y a los fieles laicos sobre el anuncio del Evangelio en el mundo actual. 
En el segundo capítulo encontramos la frase: "La dulce y confortadora alegría de evangelizar" (EG 14-18). Donde se expresa a través de frases paulinas que la misión surge en la donación del amor que da la misma vida: “El amor de Cristo nos apremia" (2 Co 5,14); “iAy de mí si no evangelizara!" (1 Co 9,16).

Se percibe un hilo conductor de fidelidad con los capítulos finales de las exhortaciones Evangelii Nuntiandi (Pablo VI, 1975, EN 74-80) al igual que Redemptoris Missio (Juan Pablo II, 1990, RM 87-91) y además se traza una espiritualidad que parte del Evangelio (Francisco, 2013a, EG 259-283) y quiere combatir con las tentaciones pastorales que se presentan (EG 79-106). Afrontando la acedia egoísta (EG 81), y el pesimismo estéril (EG 83), el sumo pontífice pretende animar "la alegría evangelizadora" (EG 84), aquella "que nada ni nadie nos podrá quitar" (EG 84). "La alegría del Evangelio que llena la vida de la comunidad de los discípulos es una alegría misionera" (EG 21). Esa alegría es la que abrevia la pastoral mística del sumo pontífice.

\subsection{La misión y reforma: la Iglesia en salida misionera}

Francisco plantea en su programa "la reforma de la Iglesia en salida misionera" (EG 17). Y es por esto que en el primer capítulo propone una "pastoral en conversión" (EG 25-33) que reproduce las propuestas hechas en Aparecida sobre la conversión pastoral y renovación misionera de las comunidades (A 365- 372). Entramos en un "estado permanente de misión" (EG 25) y esto requiere de una reforma en las estructuras comenzando desde el papado junto con el gobierno central de la Iglesia, y buscando una relación eficaz y cercana con las Iglesias particulares y los mismos episcopados (EG 32) "para que se vuelvan más misioneras” (EG 27).

El propósito de Francisco lo podemos resumir de esta manera: la Iglesia se reforma por la conversión misionera; la conversión y la misión renuevan a la Iglesia. Y se trata de evitar caer en un eclesiocentrismo como en otras épocas, ya que la Iglesia, al volverse autorreferencial, cree tener luz propia y deja de ser como la luna, sabiendo que su luz viene de Cristo, el sol que nace de lo alto e ilumina a los pueblos. Esto haciendo una reflexión creativa sobre lo que dijo Henri de Lubac, en su meditación sobre la Iglesia (1958, p. 282-287) y la advertencia que hace Francisco sobre los riesgos de la mundanidad espiritual, "que se esconde detrás de apariencias de religiosidad e incluso de amor a la Iglesia" (2013a, EG 93-97), que abarca también el clericalismo. El cual se evidencia en la ambición de "dominar el espacio de la Iglesia" (EG 95, 102) y en pretender ejercer autoridad sirviéndose, aprovechándose de los pueblos. Como lo manifestó en su primera 
homilía, recordando el ejemplo y las palabras de Jesús (Mc 10,45), cuando dijo que el servicio es el poder verdadero (Francisco, 2013c, p. 9); ya que todo aquel que ejerce la autoridad pastoral está llamado a ejercer el poder de la misericordia y no dejarse tentar por el amor al poder.

El papa Juan XXIII al comenzar el Concilio Vaticano II el 11 de septiembre de 1962, se expresó de esta manera: "Esta es solo la aurora y ya los primeros rayos del sol de oriente comienzan a entibiar nuestros corazones" (Melloni, 2009, p. 333); y recordando el hermoso símbolo que tiene el cirio pascual invitó a poner la mirada en Cristo-Luz del mundo. Y así llegó a ser su lema: "Sí, Lumen Christi, Lumen Ecclesiae, Lumen gentium". Y por eso es que Francisco ve a la Iglesia como mysterium lunae y desea que la Iglesia refleje el sol de Cristo para llegar a la aurora conciliar del medio día.

La iniciativa del anuncio del Evangelio y la vida de la Iglesia surgen de Dios y depende la primacía de su gracia que es la que ilumina siempre las reflexiones que hacemos sobre la evangelización (Francisco, 2013, EG 12, 24, 112). Para la transmisión de la fe, Francisco plantea la Nueva Evangelización y utiliza el sustantivo atracción y el verbo atraer ya que "la Iglesia no crece por proselitismo sino por atracción" (EG 14, 131, con cita de A 159).

La misión entonces es una obra del Padre que atrae en Cristo por el Espíritu Santo, María y los santos, y el testimonio de la Iglesia que proviene de la comunidad de los discípulos misioneros que se involucran, que acompañan, que fructifican y festejan sabiendo dar la vida y si es necesario, llegar al martirio dando testimonio de Jesucristo. La evangelización nace del amor de Dios y de la salida de la Iglesia Misionera (EG 24), allí el Padre llama, Cristo es quien enamora, y el Espíritu Santo es quien anima, María congrega y los santos interceden por el Pueblo de Dios.

El primado de la acción divina en la evangelización retumba cuando Francisco predica en la homilía (Galli, 2014, p. 62-65) la alegría y la ternura del Evangelio. Él deja ver la religión del pueblo que no solo cree, espera, sino que ama aquel lugar teológico donde se sitúa el predicador, puesto que "el Espíritu, que inspiró los Evangelios y que actúa en el Pueblo de Dios, inspira también cómo hay que escuchar la fe del pueblo y cómo hay que predicar en cada Eucaristía" (Francisco, 2013, EG 139; EG 122 cita A 264).

Ya Bergoglio en el 2005 hacía esta reflexión sobre la siembra y la cosecha de Dios en la comisión para América Latina (p. 302-315), cuando expresaba que el predicador es quien cosecha lo que Dios ha sembrado en el corazón de los hombres y estos llegan a ser nuevas semillas en la cultura de la Palabra de Dios. "Así como nos gusta que se nos hable en nuestra lengua materna, así también en la fe 
nos gusta que se nos hable en clave de cultura materna" (Francisco, 2013, EG 139). Porque "Un predicador es un contemplativo de la Palabra y un contemplativo del pueblo" (EG 154).

La ordenación de Francisco como presbítero fue en 1969 y como obispo en 1992, llegando a ser el primer papa posconciliar que no participó del Concilio pero que sí fue formado en el transcurso del mismo, notándose su gran influencia al citar 17 veces en la exhortación al Vaticano II: hace mención de la Lumen Gentium 7 veces (conforme con lo anunciado en EG 17), cita la Gaudium et spes, tres veces, de igual manera cita tres veces la Unitatis redintegratio, y dos veces la Dei Verbum, por lo demás, hace mención de otros documentos.

Es de notar que Francisco no entra en el debate hermenéutico sobre el Concilio pero sabe que es precisa su elaboración, su práctica urgente para la Iglesia. Es comprendido que Francisco fue designado para cumplir las reformas aplazadas del Concilio Vaticano II. Su deseo es seguir avanzando en aquella reforma tan anhelada por el Concilio y eso lo hace posible con su eclesiología pastoral y su espiritualidad misionera. Cuando fue entrevistado por la revista Civiltá Cattolica manifestó que el Concilio había hecho una relectura del Evangelio a la luz de la cultura contemporánea y que esto la hacía en definitiva apetecible. Declaró al diario romano La Repubblica que el Concilio hizo una mirada al futuro pero que aún hace falta avanzar enormemente en la apertura a la modernidad de la cultura (Francisco, 2013b, p. 3)

Para Francisco "el Concilio Vaticano II presentó la conversión eclesial como la apertura a una permanente reforma de sí por fidelidad a Jesucristo" (EG 26; cf. UR 6). Promueve la conversión a Jesucristo por "una pastoral en clave misionera" (EG 35). Y desea cumplir un sueño: "sueño con una opción misionera capaz de transformarlo todo... La reforma de estructuras que exige la conversión pastoral solo puede entenderse en este sentido: procurar que todas ellas se vuelvan más misioneras" (EG 27).

Francisco propone en su exhortación, actitudes que ayuden a una reforma y transformación como la de tener el amor como centro para la perspectiva evangelizadora (EG 10, 121, 156); y la comunión para hacer posible el desarrollo de la comunidad en medio de las diferencias (EG 117, 228, 237); la paciencia como principio que reconoce el trabajo a largo plazo, sin querer resultados inmediatos que dificulten los procesos (EG 24, 44, 223); Francisco propone que el Kerigma evangélico y la tradición eclesial lleven a la renovación (EG 26, 116, 164). Él mismo dijo en una entrevista: "Para mí, la gran revolución es ir a la raíces, reconocerlas y ver lo que esas raíces tienen que decir al día de hoy" (Cymerman, 2014, p. 6). 
Por este motivo, estas actitudes tan particulares del papa coinciden con las cuatro condiciones propuestas por Yves Congar en 1950, para avanzar a una "verdadera reforma católica" o a "un reformismo sin cisma":

La primacía de la caridad y de la finalidad pastoral; la permanencia en la comunión de la totalidad católica; la paciencia para evitar los apuros y demoras; el retorno a la tradición originaria sin caer en innovaciones por adaptaciones superficiales (Congar, 1950, p. 231).

Tal parece que Francisco conocía la propuesta hecha por el autor mencionado anteriormente.

\section{Conclusión}

En esta exhortación, Francisco anhela que todos los hombres nos comprometamos de modo radical, aunque de manera particular los creyentes, a mirar de otra manera la realidad en que vivimos. Nos invita a estar más pendientes de todos los ámbitos en los que el ser humano se encuentra.

Asume con consciencia clara que la evangelización es y tiene que ser integral y por este motivo se hace inaplazable comenzar a dialogar con la política, la cultura y la ciencia; con orientación ecuménica, es decir que nuestra tarea es inculturizar, llevar el Evangelio a todas las culturas y a todos los pueblos.

Desde esta perspectiva indica que la Iglesia latinoamericana tiene mucho que aportar a la comunidad cristiana de todo el mundo, una aportación donde se proyecta la unión de la promoción humana, el desarrollo total de la persona y la liberación histórica del hombre en el obrar y el anuncio del Evangelio. Esta cooperación se encuentra a manera de reflexión en la II Conferencia de Medellín, posteriormente de manera explícita en la Evangelii Nuntiandi de Pablo VI, incluso influye en la IV Conferencia de Aparecida, con el cardenal Jorge Mario Bergolio, actualmente Francisco, con su exhortación Evangelii Gaudium. De igual manera, nos convoca a evangelizar a partir de nuestro encuentro personal con Jesucristo y a poseer la experiencia autentica de la alegría que emana del corazón misericordioso de Cristo.

Por consiguiente, Francisco afirma que "no es lo mismo tratar de construir el mundo con su Evangelio que hacerlo solo con la propia razón (...) El verdadero misionero (...) sabe que Jesús camina con él, habla con él, trabaja con él" (Francisco, 2013, EG, 266). Debemos aceptar que el mensaje dado por el papa Francisco 
es un mensaje contundente, dinámico, directo, simple, confortante y humano con gran aprecio por el otro. Es una invitación a salir hacia el encuentro con los otros, a crear vínculos de comunión y fraternidad, al obrar dando testimonio de una vida cristiana que irradia la alegría de la Buena Nueva de Jesucristo y crear nuevas formas de cultura, paz, respeto, solidaridad y misericordia para con el prójimo.

Esta misión propuesta por Francisco es un camino que transforma, renueva, convierte y reforma. Es un mirar hacia dentro y hacia afuera a la vez. Su invitación nos propone una verdad que transforma la vida misma mientras se está de misión, somos quienes llevamos el mensaje y a su vez quienes lo recibimos. Instruimos y somos instruidos como misioneros. La misión nos enriquece como seres humanos y nos hace sensibles a los problemas o realidades de los demás.

La misión no excluye a ninguna persona y es una actitud que debe permanecer en todos los cristianos. De ahí que debemos "poner los medios necesarios para avanzar en el camino de una conversión pastoral y misionera, que no puede dejar las cosas como están" (EG 25).

Es decir, hay que decir y hacer, poner manos a la obra, ya que hechos y palabras deben ir juntos. Dios obrando en nosotros con una palabra de aliento y misericordia, que brota de Él mismo y transforma nuestra realidad y nuestra historia. En el hacer el bien predicando el amor de Dios, está la clave que nos posibilitará dejar el individualismo y restablecer la apacible y confortante alegría de evangelizar.

\section{Referencias}

Bergoglio J. M. en la plaza de San Pedro tras ser elegido Papa de la Iglesia Católica. (13 de marzo de 2013). BBC Mundo. Recuperado de: http://www.bbc.com/mundo/ noticias/2013/03/130313_livetext_hay_nuevo_papa_conclave_vaticano_ao.shtml

Bergoglio J. M. (2005). La dulce y confortadora alegría de predicar. En El verdadero poder es el servicio, Buenos Aires, Argentina: Claretiana, 2013, 2ª , pp. 302-315.

Biblia de Jerusalén (1998). Bilbao, España: Desclée De Brouwer.

CELAM. (2007). Consejo Episcopal Latinoamericano. V Conferencia del Episcopado Latinoamericano y del Caribe. Documentos conclusivos. Aparecida, Brasil: San Pablo.

Concilio Vaticano II. (2008). Documentos completos. Bogotá D. C., Colombia: Ediciones Paulinas.

Congar, Y. (1950). Vrai et fausse réforme dans l'Église, París, Francia: Du Cerf. 
Cymerman, H. (20 de junio de 2014). Entrevista al papa Francisco, L'Osservatore romano.

De Lubac, H. (1958). Meditación sobre la Iglesia. Pamplona, España: DDB.

Fernández, V., y Rodari, P. (2014). El proyecto de Francisco. Bologna, Italia: EMI.

Francisco (2013a). Exhortación Apostólica Evangelii Gaudium. Librería Editrice Vaticana. Bogotá D. C., Colombia: Ediciones Paulinas.

Francisco (2013b). Il Papa: cosí cambieró la Chiesa. La Repubblica.

Francisco (2013c). Para custodiar y acoger. Homilía en la misa en el inicio del ministerio como sucesor de Pedro. L'Osservatore romano.

Galli, C. M. (2014). Il Codice Francesco. La gioia e la tenerezza del Vangelo, Vita Pastorale 3, 62-65.

Juan Pablo II. (1995). Evangelium Vitae. Colombia: Ediciones Paulinas.

Kasper, W. (2012). La misericordia. Clave del Evangelio y de la vida cristiana. Santander, España: Sal Terrae, 2012.

Lafont, G. (1994). Historia teológica de la Iglesia católica. Itinerario y formas de teología. París, Francia: Du Cerf.

Melloni, A. (2009). Torino, Italia: Einaudi.

Pablo VI. (1975). Evangelii Nuntiandi. Bogotá D. E., Colombia: Ed. Salesiana.

Santo Domingo. Conclusiones (1992). Colombia: CEP.

Süess, P. (2010). Diccionario de Aparecida. 40 palabras claves. Bogotá D. C., Colombia: San Pablo. 